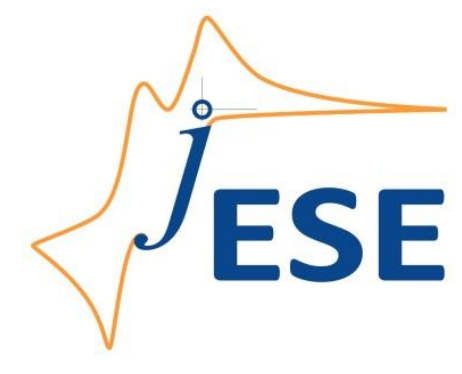

Open Access : : ISSN 1847-9286

www.jESE-online.org

Original scientific paper

\title{
Determination of nevirapine in the presence of cucurbit(7)uril with a gold electrode
}

\author{
ANA M. ESTEVA, ELÍAS BLANCO*, , JUAN J. PIÑA, ABEL I. BALBIN, CARMEN \\ QUINTANA*, PEDRO HERNÁNDEZ*
}

Departamento de Química Analítica, Facultad de Química, Universidad de La Habana, La Habana 10400, Cuba

*Departamento de Química Analítica y Análisis Instrumental, Facultad de Ciencias, Universidad Autónoma de Madrid, Cantoblanco 28049, Madrid, Spain

${ }^{\otimes}$ Corresponding Author: E-mail: elias.blanco@uam.es; Tel.: +34-91-497-4172; Fax: +34-91-497-4931

Received: July 24, 2013; Revised: November 21, 2013; Published: January 25, 2014

\begin{abstract}
The electrochemical oxidation of nevirapine, an anti-HIV drug, at a gold electrode was studied by voltammetric techniques. Nevirapine showed a signal that interfered with a working electrode wave. This interference was solved by the use of cucurbit(7)uril allowing nevirapine to be determined in tablets (80.4\% recovery, presence of stavudine and lamivudine) and urine (98.4\%).
\end{abstract}

\section{Keywords}

Antiretroviral, Voltammetry, Tablets, Urine

\section{Introduction}

Nevirapine (NEV, Figure 1) is a non-nucleoside reverse transcriptase inhibitor (NNRTI) of HIV-1 that causes acquired immunodeficiency syndrome (AIDS). The drug directly bounds to and blocks the activities of RNA and DNA polymerases, both dependent, which caused breakdown of the enzyme catalytic site. NEV activity was not competitive with the reverse transcriptase enzyme or with nucleoside triphosphates. Reverse transcriptase (RT) of HIV-2 and DNA polymerases of eukaryotic cells (eg. human DNA polymerases alpha, beta, gamma and sigma) were not inhibited by nevirapine. The in-vitro antiviral activity was determined in peripheral blood mononuclear cells (PBMC), monocyte-derived macrophages and a lymphoblastoid cell line. The values of the $50 \%$ inhibitory concentrations $\left(\mathrm{IC}_{50}\right)$ were in the range of 10 to $100 \mu \mathrm{M}$ against laboratory and clinical isolates of HIV-1. In cell cultures, nevirapine demonstrated additive to synergistic action against 
HIV-1 in combination regimens with zidovudine, didanosine, stavudine, lamivudine, saquinavir and indinavir [1].

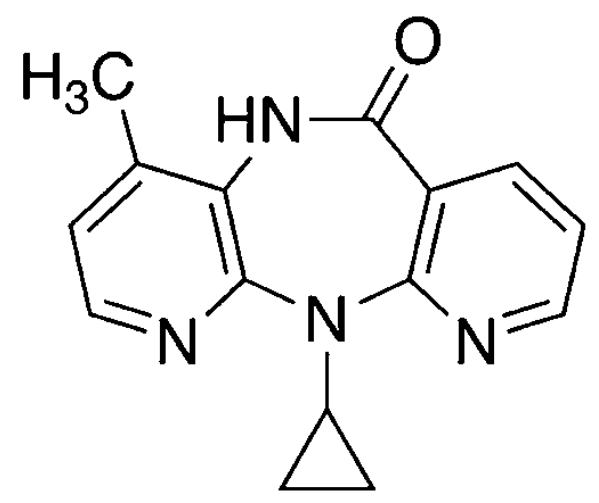

Figure 1. Nevirapine; 11-cyclopropyl-5,11-dihydro-4-methyl-6H dipyrido[3,2-b:2',3'-e]-[1,4]diazepin-6-one.

Different analytical techniques were used to detect NEV, including high performance liquid chromatography (HPLC) [2], matrix-assisted laser desorption/ionization-time of flight mass spectrometry (MALDI-TOF) [3], and capillary electrophoresis [4]. These techniques require expensive equipment, costly reagents for sample preparation and analysis and quite some time.

Electroanalytical methods are an accurate and cheap alternative which offer very low detection limits for electroactive molecules. Different drugs were determined by this technique achieving very low detection limits [5]. Some articles have recently been published about the electroanalytical determination of NEV by means of different working electrodes [6-8].

The family of compounds of cucurbit $(n)$ urils $(\mathrm{CB}(n))$ are polymeric macrocycles obtained by the condensation reaction of glicoluryl and formaldehyde in acid conditions and have $n$ units of glicoluryl bridged by methylene groups. They bind molecules by hydrophobic and ion-dipole interactions (but not exclusively) due to the cavity portals delineated by a rim of carbonylic oxygens. The hydrophobic cavity allowed the inclusion of different molecules depending on the $\mathrm{CB}(n)$ homologue and the size of the guest $[9,10]$.

We developed a method for the analysis of NEV using $\mathrm{CB}(7)$ and gold electrode. Low detection limits were obtained. The method was applied to biological fluids (urine) and a pharmaceutical formulation (which also contained lamivudine and stavudine) and it was demonstrated that the methodology had fewer steps than other ones.

\section{Experimental}

\section{Reagents}

NEV was provided by the Center for State Control of Drugs (CECMED-Cuba). Aqueous solutions of the analyte were prepared at a $2 \mathrm{mg} \mathrm{mL}^{-1}$ concentration in acid medium $(\mathrm{pH}<3)$. Diluted solutions were prepared in supporting electrolyte just before use. $\mathrm{CB}(7)$ was supplied by SigmaAldrich Chemical Co. All reagents were of analytical grade ( $>98 \%)$ and were provided by Scharlau. Ultrapure water was produced by a Milli-Ro and Milli-Q system (Millipore, Waters). Solutions of these compounds were stored at $4{ }^{\circ} \mathrm{C}$ and protected from light. Britton-Robinson buffer solutions (BR, mixture of boric, acetic and phosphoric acids) were used as supporting electrolytes, prepared at a final concentration of $0.04 \mathrm{M}$ and the buffer $\mathrm{pH}$ was adjusted with $0.1 \mathrm{M} \mathrm{NaOH}$.

NEV was determined in a tablet sample whose nominal content was $250 \mathrm{mg}$ per tablet together with $40 \mathrm{mg}$ of stavudine and $150 \mathrm{mg}$ of lamivudine. A tablet was dissolved in methanol and filtered 
through a cellulose membrane of $0.45 \mu \mathrm{m}$ pore size to get a $2.5 \mathrm{mg} \mathrm{mL}^{-1} \mathrm{NEV}$ solution which was stored at $4{ }^{\circ} \mathrm{C}$.

\section{Apparatus}

Electrochemical measurements were performed by means of a $\mu$ Autolab III potentiostat made by Eco-Chemie in a three electrodes cell: an Au working electrode ( $2.01 \mathrm{~mm}^{2}$ geometric area) provided by BAS, a coiled platinum wire as counter electrode and an $\mathrm{Ag} / \mathrm{AgCl}(3 \mathrm{M} \mathrm{KCl})$ reference electrode (all potentials in this paper were referred against it). The $\mathrm{pH}$ was controlled by means of a Methrom $827 \mathrm{pH}$ meter with combined glass and an $\mathrm{Ag} / \mathrm{AgCl} /(3 \mathrm{M} \mathrm{KCl})$ electrode.

\section{Procedure}

Activation and regeneration of the gold electrode surface was carried out by successive scanning in $0.1 \mathrm{M}$ sulphuric acid between $0.0 \mathrm{~V}$ and $1.5 \mathrm{~V}$ at $100 \mathrm{mV} \mathrm{s}^{-1}$ by cyclic voltammetry (CV). An ultrasonic bath was used to clean the electrode surface when required and prior to the described activation procedure. Differential pulse voltammetry (DPV) was the chosen technique for the analyte determination in solutions of a $\mathrm{NEV}: \mathrm{CB}(7)$ ratio of $1: 2$, the measurements started at $0.4 \mathrm{~V}$ and the chosen scan rate and pulse amplitude were $25 \mathrm{mV} \mathrm{s}^{-1}$ and $25 \mathrm{mV}$, respectively.

\section{Results and Discussion}

Our studies were performed with NEV at a concentration of $100 \mu \mathrm{M}\left(26.6 \mu \mathrm{g} \mathrm{mL}^{-1}\right)$ by CV at gold electrode in $0.04 \mathrm{M} \mathrm{BR}$ buffer at $\mathrm{pH}$ 2. The analyte showed irreversible redox behaviour and a reduction wave was observed at $0.66 \mathrm{~V}$. As it can be seen in Figure 2, a broad and intense signal at $1.14 \mathrm{~V}$ was seen in the anodic scan (green line) but close to the gold oxidation wave at $1.3 \mathrm{~V}$ (black line). It shifted to potential values lower than $1.1 \mathrm{~V}$ between $\mathrm{pH} 2$ and 6 until disappearance at higher $\mathrm{pH}$. Above that $\mathrm{pH}, \mathrm{NEV}$ was not electroactive.

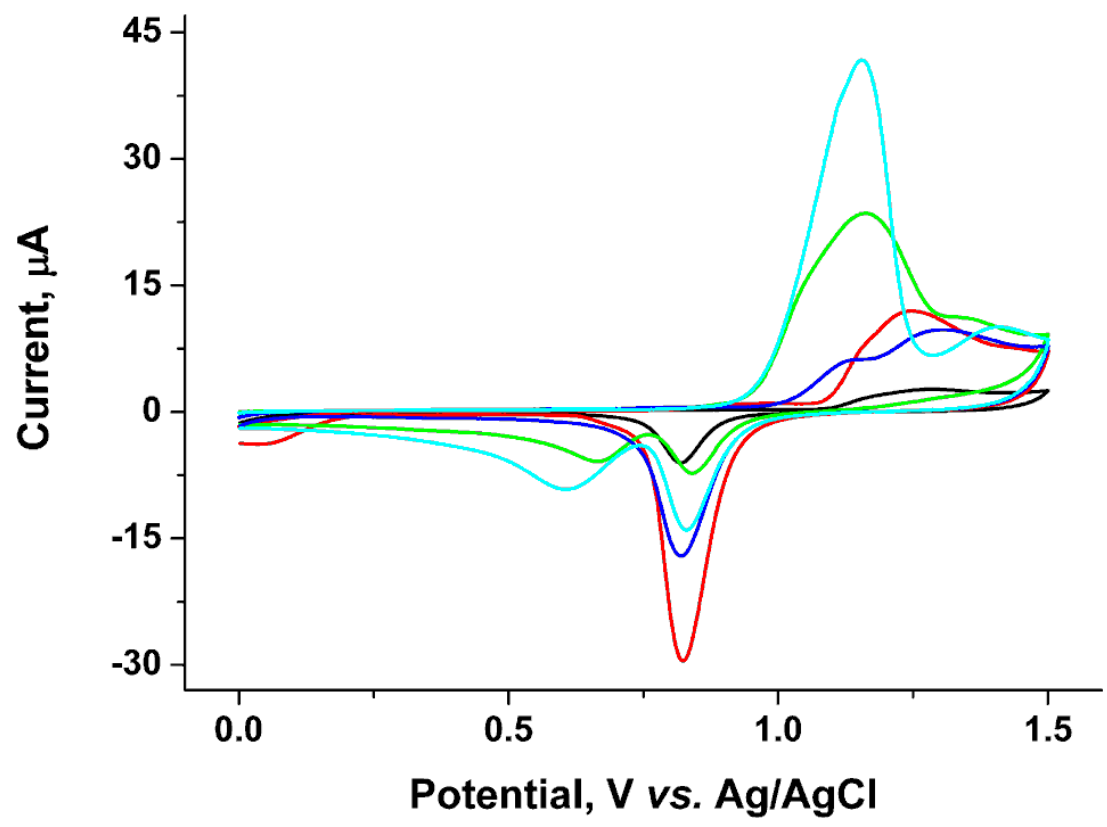

Figure 2. Cyclic voltammograms of $N E V$ at $100 \mathrm{mV} \mathrm{s}^{-1}$ in $0.04 \mathrm{M} \mathrm{BR}$ buffer at $\mathrm{pH}$ 2. Black line, supporting electrolyte; red line, $20 \mu \mathrm{M} \mathrm{CB(7);} \mathrm{green} \mathrm{line,} 100 \mu \mathrm{M} \mathrm{NEV;} \mathrm{blue} \mathrm{line,} 10 \mu \mathrm{M} \mathrm{NEV}$; cyan line, $10 \mu M$ NEV and $20 \mu M C B(7)$. 
An increase in the sweep rate $\left(V_{\mathrm{b}}\right)$ between 10 and $400 \mathrm{mV} \mathrm{s}^{-1}$ entailed a variation of the intensity and potential of the signals when a $266 \mu \mathrm{g} \mathrm{mL}^{-1}$ analyte solution in $0.04 \mathrm{M} \mathrm{BR}$ at $\mathrm{pH} 2$ was analysed. When the logarithm of the anodic peak current was represented versus the logarithm of the scan rate in Figure 3 (black points), a straight line was obtained with a 0.53 slope value (close to 0.5$)$ so the oxidation could happen after diffusion of the analyte to the electrode surface. However, it was showed in Figure 2 (green line) that NEV was oxidized by means of at least two processes and its shape was not a diffusion-like one so the 0.53 slope value was a chance. The dependence between the logarithm of the cathodic peak current of the NEV oxidation product and the logarithm of the scan rate was studied (Figure 3, red points) and a slope close to 1 was found so the reduction of that product could be concomitant with an adsorption process. Nevertheless, that wave was overlapped with the gold oxide reduction wave and both processes were connected.

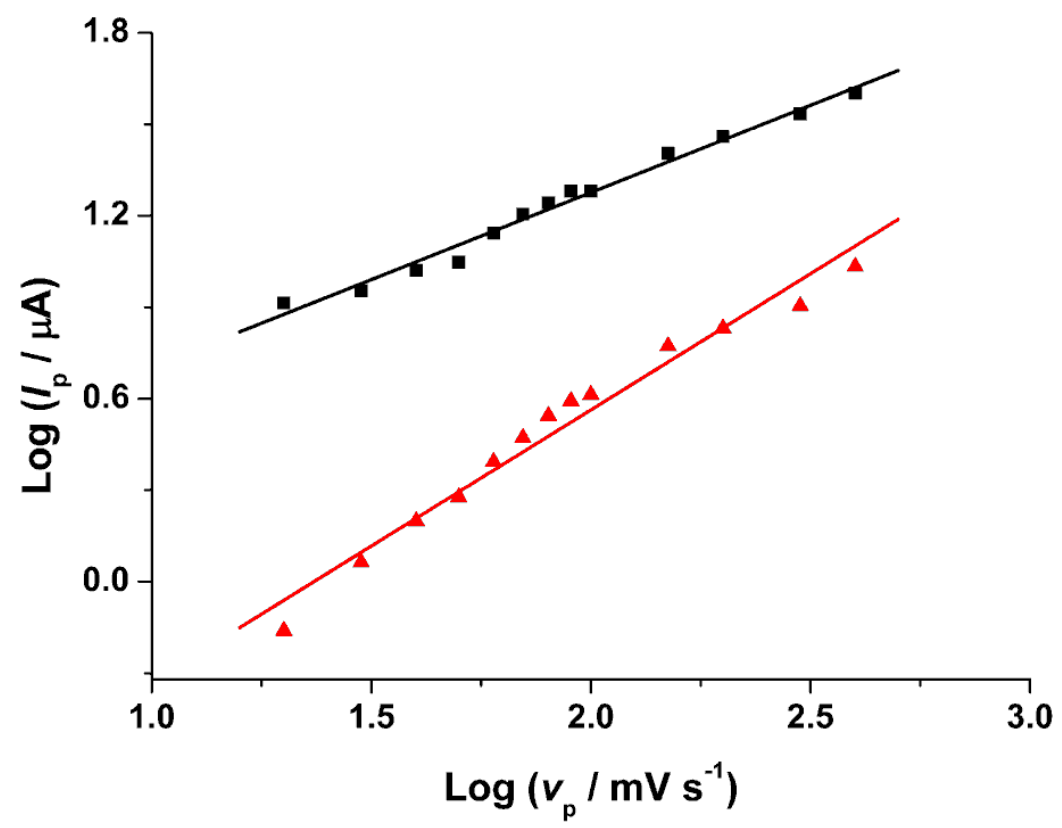

Figure 3. Effect of the change of the scan rate on the oxidation (black points and line) and reduction peak currents (red points and line).

As before stated, the NEV oxidation wave was at a potential very close to the gold oxides formation one so the measurements analysis could be complicated or even impossible if the analyte concentrations of the sample solution were low, as in the case of a $10 \mu \mathrm{M}$ NEV (blue line, Figure 2). When $\mathrm{CB}(7)$ was added to solutions of this low NEV concentration (10 $\mu \mathrm{M} N E V$ and 20 $\mu \mathrm{M} \mathrm{CB}(7)$, cyan line, Figure 2), the anodic signals were more separated, the NEV wave was narrower and a huge increase in the peak current was observed when they were compared to the signal of solutions of the same analyte concentration and no added $C B(7)$ (blue line, Figure 2). Voltammetric measurements of blank solutions of $\mathrm{CB}(7)$ did not show any signal but the same waves observed when the cell just contained supporting electrolyte, as it can be seen in Figure 2, red and black lines, respectively.

If a 1:2 NEV:CB(7) molar ratio was kept constant, the separation of NEV and gold waves in the anodic scan observed at $\mathrm{pH} 2$ in Figure 2 (cyan line) continued up to neutral $\mathrm{pH}$. In these conditions, the NEV cathodic signal was not observed at $\mathrm{pH}$ higher than 2 . The peak potential $\left(E_{\mathrm{p}}\right)$ depended on the medium $\mathrm{pH}$ so it can be concluded that the anodic reaction was coupled to an acid-base one. In this case, this dependence followed a straight line whose equation was 
$E_{\mathrm{p}} / \mathrm{V}=1.19-0.021 \mathrm{pH}\left(R^{2}=0.998\right)$. As the line slope value $\left(\mathrm{d} E_{\mathrm{p}} / \mathrm{dpH}\right)$ was close to $0.029 \mathrm{~V} \mathrm{per} \mathrm{pH}$ unit, the number of exchanged protons was the half of the number of electrons according to the Nernst equation.

The stoichiometric NEV:CB(7) ratio was studied by $\mathrm{CV}$ in $0.04 \mathrm{M} B R$ buffer $\mathrm{pH} 2$, at a constant $\mathrm{CB}(7)$ concentration and changing NEV concentration, and vice versa. Current and potential values were plotted and the slope change depending on the $\mathrm{NEV}: \mathrm{CB}(7)$ ratio was indicative of successive formation of NEV-CB(7) complexes of 1:2 stoichiometry.

As it is shown in Figure 4, the effect of the concentration $\left(0.3-1.6 \mu \mathrm{g} \mathrm{m}^{-1}\right)$ on the signal was studied at a 1:2 NEV:CB(7) ratio in $0.04 \mathrm{M} \mathrm{BR} \mathrm{pH} 2$ by DPV. Therefore, what it was done was to augment the analyte concentration but also the macrocycle one in the measured solutions. The peak current and the concentration were directly proportional up to $1 \mu \mathrm{g} \mathrm{mL}^{-1}$, data points that were fitted to $I_{\mathrm{p}} / \mu \mathrm{A}=-0.038+4.300 \mathrm{c} / \mu \mathrm{g} \mathrm{mL} \mathrm{L}^{-1}, R^{2}=0.999$. For higher concentrations the analytical signal was relatively constant probably due to surface saturation.

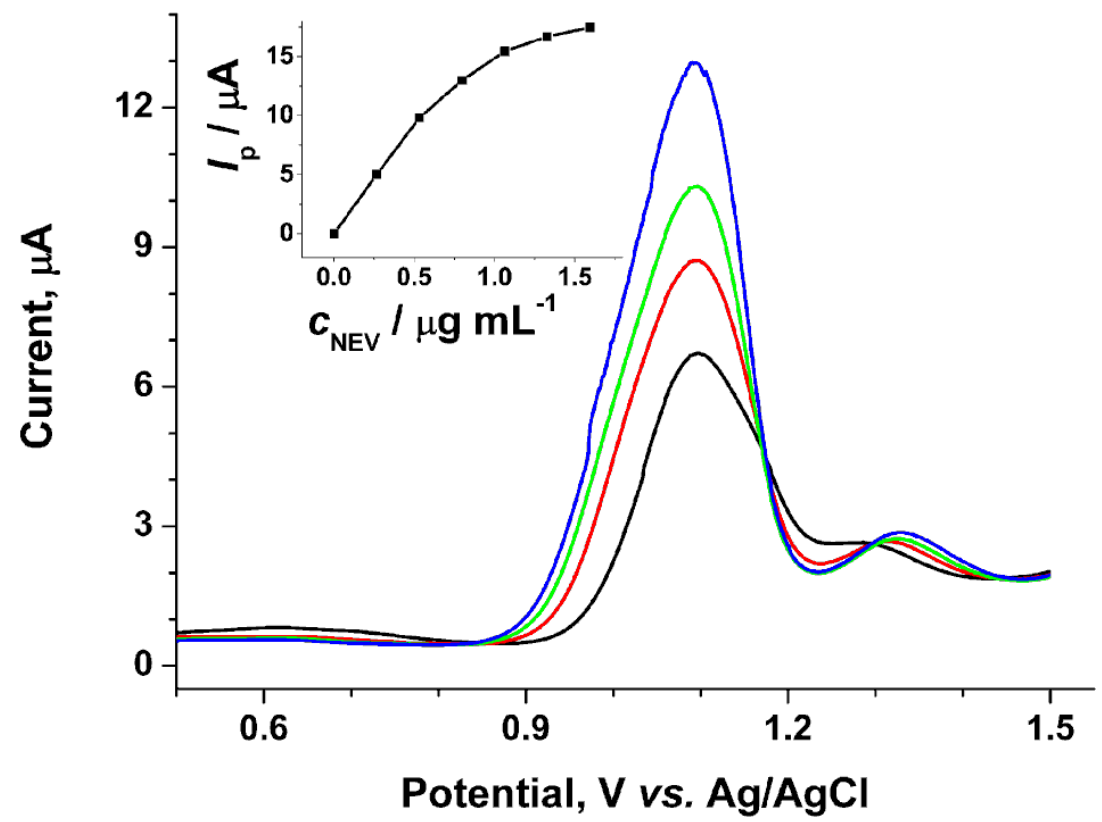

Figure 4. Effect of the concentration of NEV on the DPV measurements, at a constant $N E V: C B(7)$ ratio of $1: 2$ in $0.04 \mathrm{M} \mathrm{BR} \mathrm{pH} 2$ (see text). The voltammograms of the NEV concentrations $0.267,0.534,0.801,1.07 \mu \mathrm{g} \mathrm{mL}^{-1}$ are shown. The inset graph gives the peak current vs. NEV concentration.

CV measurements of approximately $200 \mu \mathrm{g} \mathrm{m}^{-1}$ stavudine and lamivudine solutions in $0.04 \mathrm{M} \mathrm{BR}$ were obtained at different $\mathrm{pH}$. DPV measurements of these two interferences at $\mathrm{pH} 6$ are shown in Figure 5 and it can be seen that the lamivudine reduction signal was at $-0.2 \mathrm{~V}$ (red line) and the stavudine one was at $-0.1 \mathrm{~V}$ (black line). They both were well defined when $\mathrm{CB}(6)$ or $\mathrm{CB}(7)$ were present in the solution. The signal could be a product of the possible formation of inclusion complexes. These compounds did not show oxidation signals so did not interfere in NEV determination by DPV when they were in the analysed sample. 


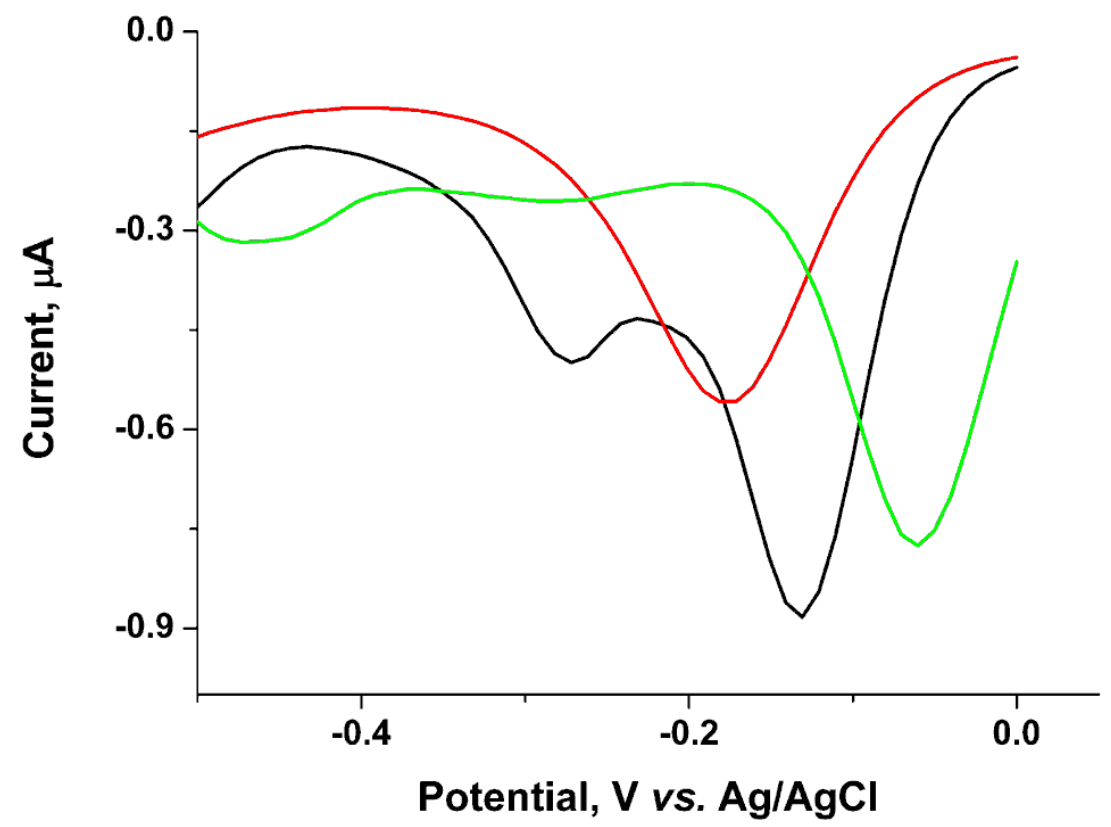

Figure 5. DPV measurements of $4 \mu M$ stavudine and lamivudine and with $C B(7)(1: 2)$ in $p H 6 B R$ buffer as electrolyte. Black line, stavudine; red line, lamivudine; green line, electrolyte.

\section{Determination in tablet}

A crushed tablet was left in contact with methanol for 24 hours, the suspension was filtered, the resulting solution was transferred to a $100 \mathrm{~mL}$ volumetric flask and the volume was completed with methanol. It contained $2.5 \mathrm{mg} \mathrm{mL}^{-1}$ of NEV and the working solutions were prepared from this one. Voltammograms of sample solutions were recorded and, as it can be seen in Figure 6 and as previously shown, the gold oxidation and NEV waves were overlapped if no $\mathrm{CB}(7)$ had been added but they were separated if the macrocycle was present (1:2 NEV:CB(7) ratio). The results obtained by means of the standard addition method showed that the content of NEV/tablet was $80.4 \%$ of the nominal one $(n=4)$ in the presence of stavudine and lamivudine.

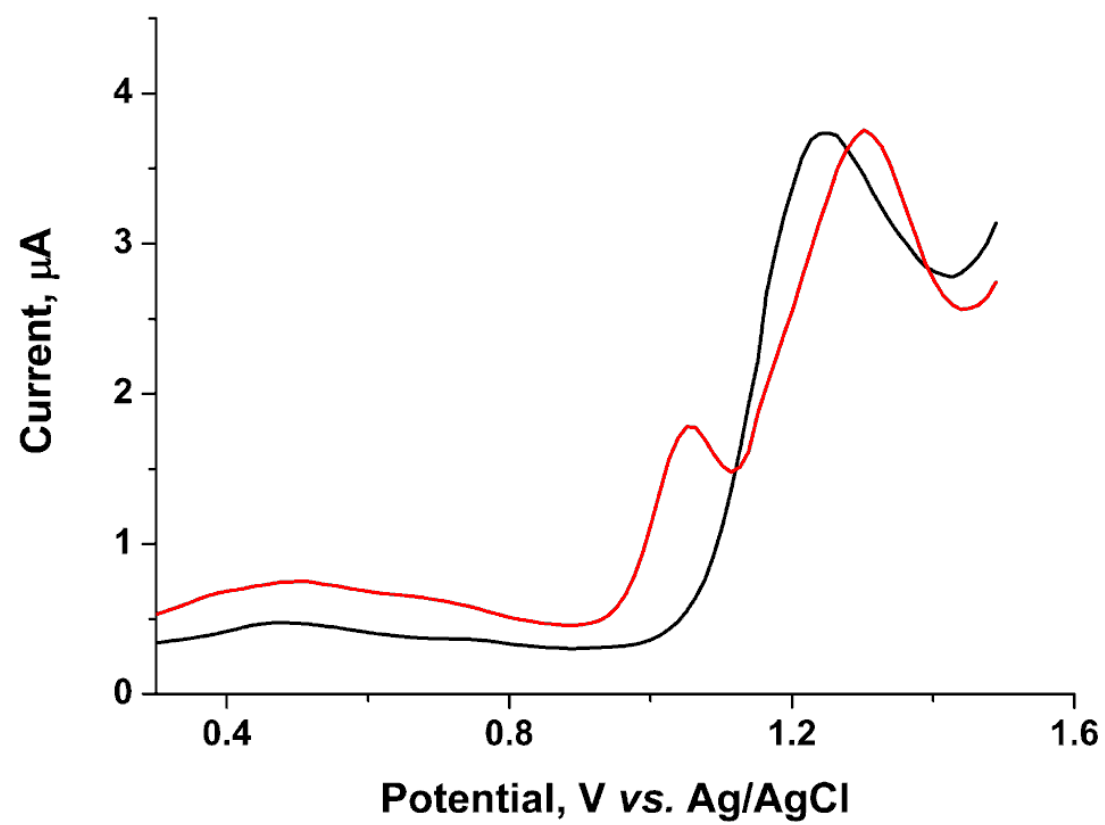

Figure 6. DPV measurements of solutions of the pharmaceutical sample in $0.04 \mathrm{MBR}$ buffer $p H$

2. Black line, no $C B(7)$ in solution; red line, with $C B(7)$ (ration 1:2 NEV:CB(7)). 


\section{Determination in urine}

A previous treatment of liquid-liquid extraction was necessary given the complexity and characteristics of the urine sample. $2 \mathrm{~mL}$ of urine of a healthy individuals were spiked with NEV to reach a final concentration of $26 \mu \mathrm{g} \mathrm{mL}^{-1}$ and were subjected to liquid-liquid extraction with $10 \mathrm{~mL}$ of diethyl ether. After shaking, the liquid was left for $3 \mathrm{~min}$, the aqueous phase was discarded and the organic one was evaporated. $10 \mathrm{~mL}$ of $0.04 \mathrm{M} \mathrm{BR}$ buffer $\mathrm{pH} 2$ were used to dissolve the residue, the solution was introduced in the electrochemical cell and DPV measurements of increasing concentrations of NEV were performed to analyse the sample, voltammograms that are shown in Figure 7. A recovery of $98.4 \%(n=3)$ was obtained for the spiked urine with $26 \mu \mathrm{gL}^{-1}$ NEV in presence of $\mathrm{CB}(7)$.

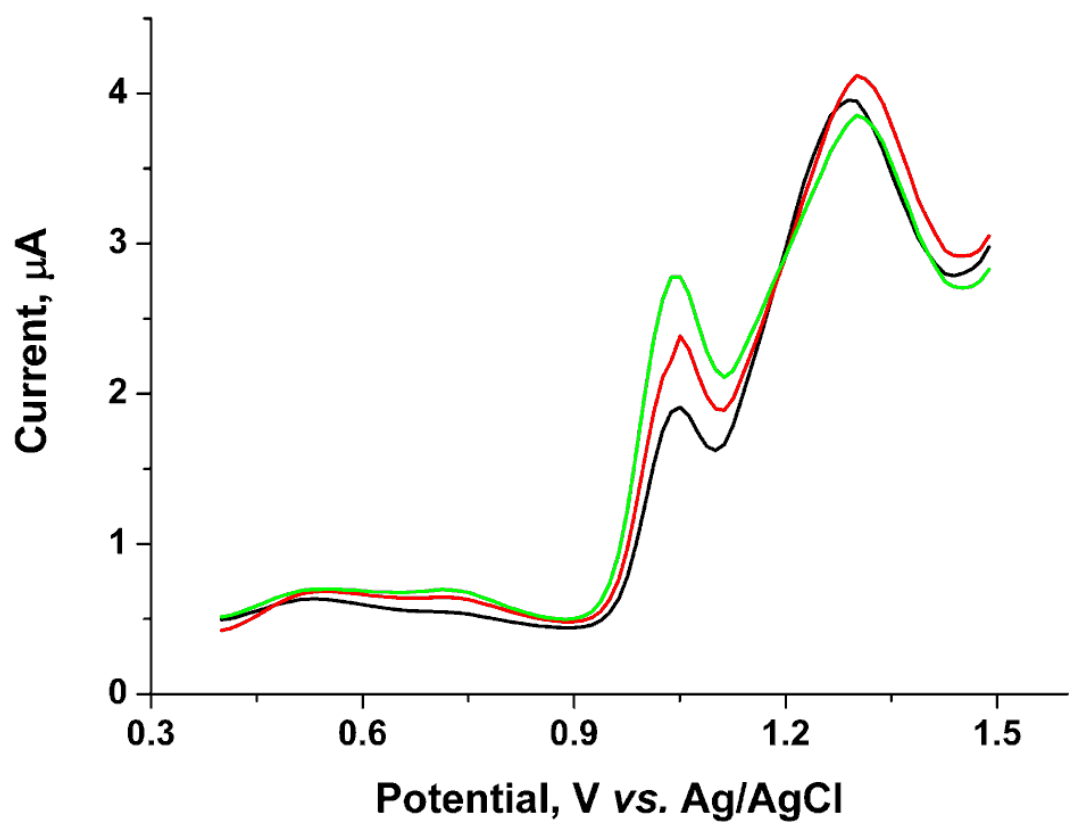

Figure 7. DPV measurements of NEV doped urine with successive additions of the drug in presence of $C B(7)$, maintaining the 1:2 ratio. Black line, $0 \mu \mathrm{g} \mathrm{mL}^{-1} \mathrm{NEV}$ added; red line, $5.32 \mu \mathrm{gL}^{-1}$; green line, $10.6 \mu \mathrm{g} \mathrm{m}^{-1}$.

\section{Conclusions}

An electroanalytical method was developed for the analysis of NEV in pharmaceutical formulations in the presence of stavudine and lamivudine and in urine by means of a gold electrode and DPV. NEV was electroactive between $\mathrm{pH} 2$ and 6 and $\mathrm{CV}$ measurements showed that NEV oxidation wave was very close to the gold oxides formation one but if $\mathrm{CB}(7)$ was added to a NEV solution, both waves were separated and an increase in the analyte peak current was observed. Measurements in $0.04 \mathrm{M} \mathrm{BR}$ buffer $\mathrm{pH} 2$ were performed to get the stoichiometry of the NEV-CB(7) complex behind this electrochemical behaviour and it was found that one NEV molecule interacted with two $\mathrm{CB}(7)$ molecules, ratio which was kept constant in every calibration or analyzed sample. The calibration of the response was performed and found the equation $I_{\mathrm{p}} / \mu \mathrm{A}=-0.038+4.300 \mathrm{c} / \mu \mathrm{g} \mathrm{mL} \mathrm{L}^{-1}, R^{2}=0.999$. The analysis of tablets gave an $80.4 \%$ recovery $(\mathrm{n}=4)$ just dissolving the sample in methanol. $2 \mathrm{~mL}$ of urine were doped with NEV at a concentration of $26 \mu \mathrm{g} \mathrm{mL}^{-1}$ and were subjected to liquid-liquid extraction due to the complex matrix and a $98.4 \%$ recovery $(n=3)$ was found. 
Acknowledgements: Authors thank to Spanish Agency for International Development Cooperation (AECID, A/030784/10) and Comunidad de Madrid (S2009/PPQ-1642, AVANSENS).

\section{References}

[1] D. Burch, Martindale - The complete drug reference, Pharmaceutical Press, London, United Kingdom, 2006

[2] V. Kabra, V. Agrahari, C. Karthikeyan, P. Trivedi, Tropical Journal of Pharmaceutical Research 8 (2009) 79-86

[3] S. Notari, C. Mancone, T. Alonzi, M. Tripodi, P. Narciso, P. Ascenzi, Journal of Chromatography B-Analytical Technologies In the Biomedical and Life Sciences 863 (2008) 249-257

[4] R. Sekar, S. Azhaguvel, Chromatographia 67 (2008) 389-398

[5] B. Dogan-Topal, S. A. Sibel, B. Uslu, The Open Chemical and Biomedical Methods Journal 3 (2010) 56-73

[6] A. A. Castro, R. Q. Aucelio, N. A. Rey, E. M. Migueland, P. A. M. Farias, Combinatorial Chemistry \& High Throughput Screening 14 (2011) 22-27

[7] N. L. Teradal, S. N. Prashanth, J. Seetharamappa, J. Electrochem. Sci. Eng. 2 (2012) 67-75

[8] F. F. Zhang, L. Li, L. Q. Luo, Y. P. Ding, X. Liu, J. Appl. Electrochem. 43 (2013) 263-269

[9] J. Lagona, P. Mukhopadhyay, S. Chakrabarti, L. Isaacs, Angew. Chem. Int. Ed. 44 (2005) 4844-4870

[10] E. Masson, X. X. Ling, R. Joseph, L. Kyeremeh-Mensah, X.Y. Lu, RSC Advances 2 (2012) 12131247

(C) 2014 by the authors; licensee IAPC, Zagreb, Croatia. This article is an open-access article distributed under the terms and conditions of the Creative Commons Attribution license (http://creativecommons.org/licenses/by/3.0/) (cc) EY 